Geopolítica(s) Revista de estudios sobre espacio y poder ISSN: 2172-3958

https://dx.doi.org/10.5209/geop.69361

\title{
Confinamiento/aislamiento: del lenguaje preventivo de la COVID-19 a la pragmática de la guerra en Colombia
}

\author{
Vladimir Montoya Arango ${ }^{1}$
}

Recibido: 9 de mayo de 2020 / Aceptado: 10 de mayo de 2020

Resumen. En Colombia la COVID-19 llegó hasta territorios históricamente marginalizados y afectados por la disputa territorial actual entre grupos armados ilegales y guerrilla. Del lenguaje preventivo del confinamiento y el aislamiento social como mecanismos de contención del contagio, se derivan amenazas para los planes de vida de las comunidades que plantean retos para la construcción de paz durante y después de la pandemia.

Palabras clave: pandemia de COVID-19; Colombia; guerrilla; paz; confinamiento.

\section{[en] Confinement/Isolation: From the Preventive Language of COVID-19 to the Pragmatics of the War in Colombia}

\begin{abstract}
In Colombia, COVID-19 reached historically marginalized territories affected by the current territorial dispute between illegal armed groups and guerrillas. From the preventive language of confinement and social isolation as mechanisms to contain the contagion derive threats to the life plans of communities and, in turn, pose challenges to the construction of peace during and after the pandemic.
\end{abstract}

Keywords: COVID-19 pandemic; Colombia; guerrilla; peace; lockdown.

\section{[pt] Confinamento/isolamento: da linguagem preventiva da COVID-19 às pragmáticas da guerra na Colômbia}

Resumo. Na Colômbia, a COVID-19 alcançou territórios historicamente marginalizados afetados pela atual disputa territorial entre grupos armados ilegais e guerrilheiros. Da linguagem preventiva do confinamento e do isolamento social como mecanismos de contágio, derivam ameaças aos planos de vida das comunidades que apresentam desafios para a construção da paz durante e após a pandemia.

Palavras-chave: pandemia da COVID-19; Colômbia; guerrilha; paz; confinamento.

Sumario. Introducción. 1. El «confinamiento» de la guerrilla. 2. El proceso de paz y la pandemia. Reflexiones finales. Referencias.

1 Profesor Titular y Director del Instituto de Estudios Regionales, Universidad de Antioquia, Colombia.

E-mail: vladimir.montoya@udea.edu.co 
Cómo citar: Montoya Arango, V. (2020). Confinamiento/aislamiento: del lenguaje preventivo del COVID-19 a la pragmática de la guerra en Colombia. Geopolítica(s). Revista de estudios sobre espacio y poder, 11 (Especial), 285-291.

\section{Introducción}

Con asombro y desazón recibimos en Colombia las alertas humanitarias emitidas por comunidades locales asediadas por grupos armados en Antioquia, Chocó y Córdoba, en el noroccidente del país, que anunciaban el regreso del desplazamiento forzado, una trágica estrategia de control territorial que parecía haber terminado tras la firma del Acuerdo de Paz entre el Gobierno Nacional y las FARC-EP y que en 2019 reapareció como cruel consecuencia de las disputas entre grupos armados. En noviembre pasado, OCHA lo registró de esta manera: "Amenazas contra población civil por parte de las disidencias FARC-EP en alianza con el grupo "Los Caparrapos" en zona rural del municipio de San José de Uré (Córdoba), han ocasionado el desplazamiento masivo de al menos 225 personas (65 familias) pertenecientes a comunidades indígenas y campesinas de diferentes veredas" (OCHA, 2019).

Seguidamente, alertaría también sobre la crisis del «confinamiento» producida por el asedio de los grupos armados que provocan el repliegue de las comunidades hacia sus sitios de habitación como forma de autoprotección, limitando sus circuitos de movilidad y de trabajo, impidiendo la consecución de alimentos en las parcelas y en los ríos, obstruyendo el acceso a servicios de salud y educación y, haciendo riesgosa la ida a las cabeceras municipales donde participan en organizaciones sociales, visitan a sus familiares, se aprovisionan de alimentos e insumos agropecuarios o realizan trámites ante instituciones estatales.

\section{El «confinamiento» de la guerrilla}

Cuando apenas despuntaba el 2020, en el medio curso del río Atrato, en límites de los departamentos de Antioquia y Chocó, el «confinamiento» llegó como mandato de la guerrilla del ELN y del Clan del Golfo, llegados hasta allí para disputarse los que fueran territorios controlados por las FARC-EP antes del Acuerdo de Paz. Así lo denunciaba Luis Darley Cuesta, Secretario de Gobierno del municipio de Vigía del Fuerte: "No hemos obtenido una respuesta contundente de este llamado que viene haciendo nuestro señor alcalde sobre que la misma comunidad hoy están confinados, se sienten amenazados, intimidados. Hoy ya se están presentando desabastecimiento alimenticio, entonces hoy la gente no tiene la garantía de salir a la parte rural al monte ni a sus fincas" (Radio Caracol, 2020). A continuación, advertía que del «confinamiento» se sigue el desabastecimiento alimentario y esto ocasionaría el desplazamiento forzado de cerca de 350 familias de tres comunidades afrodescendientes y una comunidad indígena Emberá. Fue así como, aún antes de aparecer la pandemia del COVID-19, las comunidades étnicas en sus territorios ya mostraban una alta vulnerabilidad y advertían los efectos graves del «confinamiento» sobre sus posibilidades de vida. 
Mientras el Gobierno Nacional se alistaba para emprender acciones de contención de la pandemia, la guerrilla del ELN a través de su "frente de guerra Jaime Toño Obando", circuló una "orden urgente a toda la población", fechada el 20 de marzo en las montañas de Colombia, en la que declaró toque de queda obligatorio en todo el país y por tiempo indefinido por motivo del COVID-19, con lo cual, en las zonas bajo su control territorial, limitaron la movilidad y establecieron el «confinamiento» obligatorio de las comunidades rurales en las áreas bajo su dominio territorial armado. Un mes después, se reportó el desplazamiento forzado de 70 familias indígenas Emberá en el municipio de Urrao (Antioquia), como consecuencia de enfrentamientos entre grupos armados ilegales (ELN y Clan del Golfo), tal y como lo afirmó Alexis Espitia de la Organización Indígena de Antioquia: "La situación de orden público es compleja, y es posible que puedan ocurrir más desplazamientos en tres resguardos, alrededor de 13 comunidades indígenas, por lo cual al menos 3.000 personas estarían en riesgo debido a los enfrentamientos de grupos armados ilegales" (Zambrano, 2020). Con esto, se hacía realidad la implacable crudeza del desplazamiento forzado, aún en medio del «confinamiento» y «aislamiento social preventivo», decretado ya para entonces por el Gobierno Nacional, pero que no puede obedecerse desde los territorios en los que la guerra no cesa y es una amenaza mayúscula que supera el temor al intangible virus. Cientos de familias indígenas, afrodescendientes y campesinas, desplazándose por el curso de los ríos hacia las cabeceras urbanas de Urrao y Vigía del Fuerte en el departamento de Antioquia, pasaron de ser amenazadas por los grupos armados, a ser una amenaza para el contagio, sufriendo una nueva victimización en la que subyace una desconexión irreflexiva de las medidas de la salud pública globalizada con las realidades socioespaciales de la guerra en el curso medio del río Atrato.

\section{El proceso de paz y la pandemia}

En el caso de Colombia, con la tensión existente entre un proceso de paz en plena implementación y una disputa territorial abierta entre actores armados ilegales y subversión, la pandemia del COVID-19 no llegó únicamente a afectar las condiciones de salud colectiva y a exponer las inequidades del capitalismo - lo cual ha sido anunciado ampliamente por diversos analistas - , sino que, ha demostrado también el recrudecimiento de las acciones bélicas y la implantación de medidas de coerción producto del abuso estratégico del lenguaje preventivo instrumentalizado para el control territorial armado. Una vez fueron dispuestas las medidas preventivas en la fase de contención de la propagación del virus, la evidencia de la continuidad de las afectaciones sobre comunidades y líderes sociales llevó al jefe de la Misión de Verificación de la ONU en Colombia, Carlos Ruiz Massieu, a afirmar:

Debemos asegurar que comunidades, especialmente las víctimas, sigan estando al centro de esfuerzos de consolidación de la paz. Ningún esfuerzo debe escatimarse para garantizar la seguridad y protección en los territorios. Momento en que esfuerzos deben centrarse en lucha contra pandemia, instamos a todos los grupos armados ilegales de Colombia a que desistan de seguir perpetrando actos de violencia contra comunidades vulnerables, incluidas comunidades indígenas y afrocolombianas (Angarita, 2020) 
Massieu, había advertido que la pandemia tendría una fuerte repercusión en el proceso de paz, que se mantenían los ataques contra comunidades y líderes sociales y que tres excombatientes de las FARC-EP habían sido asesinados, llegando a 195 asesinados desde la firma del Acuerdo de $\mathrm{Paz}^{2}$. A su vez, el Instituto Kroc en un comunicado de sus codirectores David Cortright y Josefina Echavarría, hacía énfasis en que los efectos del COVID-19 son mayores entre las poblaciones marginadas donde son mayores las carencias de servicios de salud y enfatizó que la atención de la pandemia podría afectar la implementación del Acuerdo de Paz: "Las consultas y reuniones que forman parte del proceso se han retrasado o se realizan en línea. Los servicios de reintegración para excombatientes se han ralentizado" (Vanguardia, 2020). Con acierto estas advertencias vinieron a poner de presente que las afectaciones del COVID-19 se intensifican en aquellas comunidades que, como las descritas al inicio de este artículo, están sujetas al control territorial de los grupos armados o, en los denominados Espacios Territoriales de Capacitación y Reincorporación (ETCR), creados tras el Acuerdo de Paz para la reincorporación de los excombatientes de las FARC-EP, como por ejemplo el denominado ETCR Silver Vidal Mora, ubicado en el corregimiento Las Brisas, municipio del Carmen del Darién (Chocó), que es colindante con las zonas del «confinamiento» y desplazamiento forzado descritas antes, y en el cual: "viven 186 personas, entre exguerrilleros, exguerrilleras y sus familiares" (Bonza, 2019).

Esta situación crítica de amenazas a los excombatientes y a los espacios que habitan, ha llevado a que incluso el Secretario General de Naciones Unidas Antonio Gutérres advierta al Gobierno Nacional que: "sólo tendrá éxito si todos y cada uno de los excombatientes que siguen comprometidos con el proceso de paz reciben oportunidades, protección y seguridad, independientemente del lugar donde vivan" (ONU, 2020a). Gutérres también llamó la atención sobre la vulnerabilidad de los espacios territoriales durante la pandemia y alertó sobre la necesidad de que se cumplan los compromisos pactados, especialmente aquellos relacionados con el acceso a la tierra y los proyectos productivos, los cuáles son una estrategia clave para que los excombatientes se mantengan en el proceso de reincorporación, además de que generan redes de trabajo colaborativo con las comunidades circundantes.

Es precisamente sobre esas redes de confianza entre comunidades, excombatientes en proceso de reincorporación e instituciones del sistema integral de construcción de paz, sobre las que se advierten los efectos negativos de las medidas de «confinamiento» y «aislamiento social preventivo» por el COVID-19. Aquello que aparece como un lenguaje profiláctico para la contención del contagio en las ciudades y áreas conectadas al circuito productivo del país, llega hasta los territorios bajo control territorial armado y a las zonas dispuestas para la construcción de paz, como un dispositivo punitivo que incrementa la exposición a riesgos como el desaprovisionamiento alimentario, la incursión de grupos ilegales, los atentados directos contra líderes y lideresas sociales y, además, representa un freno al accionar de las entidades que componen el sistema integral de justicia, verdad, reparación y construcción de paz en el país, tal y como apunta Torrado: “En los apartados

2 Mientras culminaba la revisión de este manuscrito, el Partido FARC denunció en su cuenta de Twitter el asesinato de un excombatiente en el municipio de Bello, llegando a 27 asesinados en el departamento de Antioquia y 196 en todo el país tras la firma del Acuerdo de Paz. 
de la justicia y la memoria, el país ha podido asomarse a una verdad tan dolorosa como reparadora, con avances como las exhumaciones de presuntas víctimas de ejecuciones extrajudiciales en Dabeiba, Antioquia, a principios de año. Ese proceso también ha perdido impulso con las medidas de aislamiento social" (Torrado, 2020). Además, pueden citarse otros ejemplos de este freno al accionar de las instituciones ligadas a la construcción de paz, como la suspensión de los procesos de restitución de tierras y el cese de actividades de verificación en el campo de las acciones contenidas en las demandas o las dificultades que plantea para la Comisión de la Verdad recibir los relatos de las víctimas sin poder entrevistarse directamente con ellas.

\section{Reflexiones finales}

En estas condiciones, los imperativos de «confinamiento» y «aislamiento social preventivo», aparecen como talanqueras a la implementación del Acuerdo de Paz, además en el contexto de un Gobierno que en ocasiones anteriores se ha mostrado contrario al cumplimiento de lo pactado y que ahora no aparece dispuesto a adecuar las medidas de contención y mitigación de la pandemia con un "enfoque de paz territorial", aunque dio un apoyo inusitado al proceso de paz al rechazar la propuesta del representante Edward Rodríguez del partido de derecha Centro Democrático, quien planteó: “[...] que los dineros que están previstos para la implementación del acuerdo de paz, sean utilizados en la financiación de algunos programas que se necesitan implementar en medio de la pandemia" (Jerez, 2020). La comunidad internacional garante del proceso de paz, ha mantenido su voluntad de contribuir al logro efectivo de lo pactado y, en medio de la crisis sanitaria del COVID-19, anunció la entrega desde finales de abril de 4.6 millones de dólares a través del Fondo Multidonante de las Naciones Unidas para el Sostenimiento de la Paz, con destinación específica para las medidas de prevención del contagio de personal de salud de los 170 municipios con Planes de Desarrollo con Enfoque Territorial (PDET) y, fortalecimiento de los hospitales públicos y de la vigilancia epidemiológica en los 26 municipios aledaños a los ETCR (ONU, 2020b). Asimismo, la misión MAPP/OEA ha reiterado el llamado a que cesen los enfrentamientos, las afectaciones a la sociedad civil, la infraestructura y el ambiente y a que se respete la integridad del personal médico que trabaja en la contención de la pandemia, enfatizando que: "En este difícil escenario, en el que se reafirma la urgente necesidad de la paz completa, la Misión reitera su compromiso de seguir apoyando, bajo las actuales medidas de contingencia, a las comunidades e instituciones de Colombia" (MAPP/OEA, 2020).

Según lo expuesto hasta aquí, es posible postular que en Colombia, en los territorios creados por el Acuerdo de Paz para la reincorporación de excombatientes, así como en los diversos territorios de comunidades étnicas, afrodescendientes y campesinas, se está sufriendo un alto riesgo derivado del accionar bélico de grupos armados ilegales y guerrilla. Hasta allí ha llegado también el riesgo epidemiológico de la pandemia del COVID-19, poniendo nuevamente en evidencia las condiciones de desigualdad e inequidad histórica de los territorios marginalizados del país, además, demostrando una afectación escalar diferencial que aumenta la letalidad del virus, pues allende la inminente posibilidad del contagio, la encrucijada del 
«confinamiento» y el «aislamiento social preventivo», resultan en riesgos enormes para los planes de vida y la pervivencia con dignidad en los territorios. En estas condiciones, las medidas de salud pública y de prevención y contención del contagio, deberán adecuarse a unas comunidades resilientes, históricamente capaces de confrontar la crudeza de la guerra, vulnerables ante la limitación de sus derechos territoriales $\mathrm{y}$, ante todo, persistentes en su imaginación esperanzada de una paz completa, estable y duradera. De allí, un desafío más para la anhelada postpandemia.

\section{Referencias}

Angarita, J. (2020). COVID-19-19 está impactando el proceso de paz: ONU. RCN Radio, 14 de marzo. Recuperado de https://www.renradio.com/internacional/COVID-19-19esta-impactando-el-proceso-de-paz-onu

Bonza, L. (2019). Un teatro en la selva que une comunidades. Hacemos Memoria, 28 de octubre. Recuperado de http://hacemosmemoria.org/2019/10/28/un-teatro-en-la-selvaque-une-comunidades-etcr-silver-vidal-mora/

Jerez, D. (2020). Descartan que recursos de la paz se destinen para atender emergencia sanitaria. $L a \quad F M, \quad 29$ de abril. Recuperado de https://www.lafm.com.co/colombia/descartan-que-recursos-de-la-paz-se-destinen-paraatender-emergencia-sanitaria

MAPP/OEA. (2020). MAPP/OEA condena situación de violencia y llama a la Paz en Colombia. Misión de Apoyo al Proceso de Paz en Colombia / OEA, 29 de marzo. Recuperado de https://www.mapp-oea.org/mapp-oea-condena-situacion-de-violencia-y-llamaa-la-paz-en-colombia/

OCHA. UN Office for the Coordination of Humanitarian Affairs. (2019). Colombia: Desplazamientos masivos en San José de Uré (Córdoba). Reliefweb, 16 de noviembre. Recuperado de https://reliefweb.int/report/colombia/colombia-desplazamientos-masivosen-san-jos-de-ur-c-rdoba-flash-update-no-1-16112019

ONU. (2020a). La pandemia de coronavirus planteará muchos retos a Colombia para lograr el acuerdo de paz. Reliefweb, 14 de abril. Recuperado de https://reliefweb.int/report/colombia/la-pandemia-de-coronavirus-plantear-muchosretos-colombia-para-lograr-el-acuerdo-de

ONU. (2020b). Fondo ONU para el sostenimiento de la paz destina \$ 4,6 millones de dólares para enfrentar el COVID-19-19 en los (A)ETCR y municipios PDET. Naciones Unidas, 20 de abril. Recuperado de https://nacionesunidas.org.co/noticias/comunicadosde-prensa/fondo-onu-para-el-sostenimiento-de-la-paz-destina-46-millones-de-dolarespara-enfrentar-el-COVID-19-19-en-los-aetcr-y-municipios-pdet/

Radio Caracol. (2020). Vigía del Fuerte advierte sobre un posible desplazamiento masivo. Radio Caracol, 24 de febrero. Recuperado de https://caracol.com.co/emisora/2020/02/25/medellin/1582605400_250196.html

Torrado, S. (2020). La parálisis del coronavirus amenaza con contagiar la paz en Colombia. El País, 8 de abril. Recuperado de https:/elpais.com/internacional/2020-04-08/laparalisis-del-coronavirus-amenaza-con-contagiar-la-paz-en-colombia.html

Vanguardia (2020). ¿Cómo afecta la epidemia de COVID-19-19 a la implementación de la paz en Colombia? Vanguardia, 15 de abril. Recuperado de 
https://www.vanguardia.com/colombia/como-afecta-la-epidemia-de-COVID-19-19-ala-implementacion-de-la-paz-en-colombia-DB2245498

Zambrano, D. (2020). Más de 70 familias indígenas fueron desplazadas en Urrao. El Colombiano, 28 de abril. Recuperado de https://www.elcolombiano.com/antioquia/desplazamiento-forzado-de-familiasindigenas-en-urrao-HK12905130 